\title{
What's wrong with medical Education in Britain?
}

\author{
Stella Lowry
}

This is the first in a series of articles examining the problems in medical education and their possible solutions.
Something is seriously wrong with medical education in Britain. Professor Lesley Rees, dean of St Bartholomew's Hospital Medical College, London, recalls with horror the transformation of eager, motivated school leavers into narrow minded, disillusioned medical graduates. "Immediately I became sub-dean at Barts there was a great stamping of feet into my office, with complaints about everything. I cannot remember half of them, but it was a depressing experience to hear young men and women complaining of all the inadequacies that they perceived in the educational process that they had been through for five years." The General Medical Council admits that the traditional medical course is stifling students: "Imagination and curiosity are soon dulled and learning patterns quickly adapt to the need to absorb knowledge, often at a superficial level...." A recent national consensus inquiry organised by the King's Fund confirmed that such worries about the undergraduate medical curriculum are widespread: "There is widespread agreement that present curricula are grossly overcrowded with factual information which soon becomes out of date and inhibits students from developing into creative critical thinkers and problem solvers."

\section{Faulty approach to medical education?}

This crisis in medical education is part of a wider crisis in medicine. Data from UCCA (Universities' Central Council on Admissions) confirm that fewer people are applying to study medicine despite large increases in applications for tertiary education as a whole. Increasing numbers of doctors are admitting to being stressed and disillusioned by their jobs, ${ }^{34}$ many regretting their choice of career. ${ }^{5}$ The recent Doctors to $B e$ series on BBC television (following medical students through their course at St Mary's Hospital Medical School, London) provided ample evidence of this disenchantment: "It could have been such a wonderful thing to be a doctor-but it's not. It's just a disaster." ${ }^{\prime 6}$ The undergraduate medical course is often identified as contributing to this demoralisation by deadening the students' initial enthusiasm and failing to prepare them adequately for the realities of professional life. ${ }^{\text {? }}$

Is this criticism justified, and can we reverse some of the recent trends by changing our approach to medical education?

In this series of nine articles I shall explore some of the most important themes in medical education. During my researches I have visited medical schools in Britain and abroad and have discussed the current problems and possible solutions with medical students, academic teaching staff, deans, NHS doctors, professional educationalists, people who have already introduced innovative schemes into medical courses, and representatives of official bodies like the GMC and the BMA.

I have learnt a lot about how the current problems are perceived and where possible solutions might lie. I now want to introduce some of the basic principles, debunk a few myths, highlight innovative schemes, and explain some of the educational jargon. I am not

\section{Traditional British medical course}

The traditional British medical course was divided into three parts. The first part lasted one year and consisted of the premedical sciences of chemistry, physics, and biology (1st MB). The 2nd MB course occupied two years, during which the preclinical sciences of biochemistry, anatomy, and physiology were studied. The clinical course occupied the final three years and led to the qualification MB, BS (bachelor of medicine and surgery).

Few schools still offer a premedical course, and the usual medical course now occupies five years and is equivalent to the 2 nd and 3 rd MBs.

Most schools provide an opportunity for selected students to spend an additional intercalated year studying for the degree of bachelor of science (BSc) or bachelor of medical science (BMedSci) during the course, and about a fifth of medical students take up this option. Some schools now offer a BMedSci as a routine part of the medical course for all of their students.

Traditionally medical students spend their preclinical years in the medical schools, where they are taught by university staff who are rarely medically qualified. The clinical teaching has, however, always been based in NHS hospitals, where the clinical academic staff hold honorary NHS appointments. Thus the Department of Health has an interest, if little direct control, in the process of medical education.

On completion of the undergraduate course a doctor obtains provisional registration with the GMC but can practice independently only after a further year of apprenticeship in approved posts. This preregistration year provides "general clinical training," which combines with the undergraduate course to form what is known as "basic medical education." Traditionally a doctor who had completed basic medical education and obtained full registration could work as an independent medical practitioner.

writing for the professional medical educators but for the vast majority of doctors for whom teaching is part of their daily lives but who are too often excluded from the current debates. I shall concentrate on basic medical education (the undergraduate course and the preregistration year), though I realise that medical education is an ongoing, ideally lifelong activity and that any end point is arbitrary.

\section{What are the problems?}

The problems in medical education permeate every aspect of the system. Even before students arrive at medical school problems have started. In recent years there has been a steady drop in the number of people applying to study medicine, despite increasing applicants for other university courses. Overall there are only two applicants for each place in British medical schools each year. Possible explanations include the recent publicity given to the junior doctors' hours of work campaign, recognition that many doctors regret their choice of careers, ${ }^{5}$ and changes in the public's attitude to the medical profession, with some loss of the traditional awe associated with being a doctor. There has also been a reduction in the relative earning power

\section{London WC1H 9JR}

Stella Lowry, assistant editor

BMF 1992;305: 1277-80 


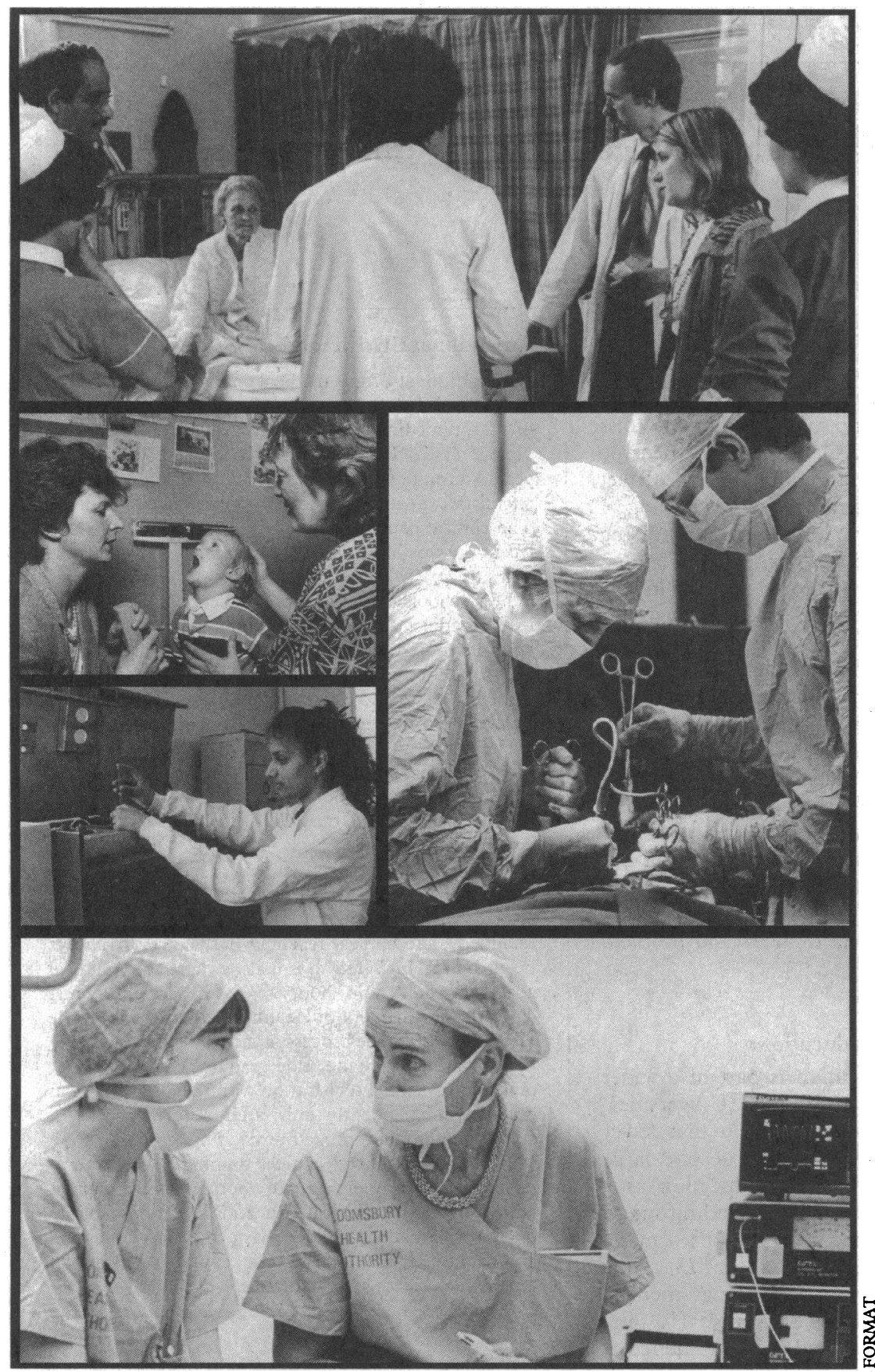

Doctors: now expected to work in multidisciplinary teams, not automatically as their leaders

of doctors compared with other professionals, and the student loan scheme and the recession are additional financial disincentives for people contemplating a long university course with short holidays in which they cannot hope to supplement their incomes by taking holiday jobs.

Then there are the problems of selecting those applicants who will be accepted on to the courses. Despite the time, effort, and money that many schools invest in their selection processes, few have staff who are properly trained in selection theory and techniques, and in many cases the processes are amateurish and depend more on luck than design for their success. This does not, however, mean that schools should spend a lot of effort in training staff to select students. Given the huge range of career options open to newly qualified doctors and the fact that all specialties in Britain now have formal postgraduate training schemes, it may be a waste of time to agonise too much about the type of student who should be allowed to enter the course. In view of the small pool of applicants available it seems unlikely that changing the selection process will have a major impact on the end product
I shall explore this dilemma in more detail next week.

\section{What and how should we teach?}

Perhaps the most difficult problem facing medical education is deciding how the course should be adapted to meet changing needs. The GMC and the King's Fund inquiry have identified curriculum overload as a major problem. Medical facts go out of date so quickly and medical information expands so fast that the most important skill for medical students to acquire is probably the ability to identify gaps in their knowledge and go about finding out for themselves the answers to the problems they face. Only then can they hope to be able to keep up with the changes that will occur during their professional lives.

The GMC has called for the introduction of a "core curriculum" taking up about two thirds of the total curriculum time, with the remainder available for students to pursue their own interests and study "options" in depth (box). ${ }^{1}$ This leaves the medical schools with the huge problems of defining the core that all students must study and introducing facilities to encourage them to make good use of their private study time. A plethora of techniques for implementing such changes has grown up, and terms like "problem based," "self directed," and "student centred" abound in discussions about curriculum reform. Do these strategies really hold the key to successful changes in undergraduate teaching, and is the use of such jargon essential to clear discussion of the possible solutions or merely an elitist muddying of the waters that effectively excludes the doctors who do most of the teaching from contributing to the debates? Later in this series I shall look at some of the suggested aims and strategies for reform of medical curricula. In particular, I shall discuss the SPICES model proposed by Professor Ron Harden, of the Centre for Medical Education at the University of Dundee, which is a valuable tool in weighing the pros and cons of some of the currently fashionable techniques. ${ }^{8}$

If schools do decide to adopt new teaching strategies do they have the staff to implement them? Experts in medical education, like Professor Harden, emphasise the need for staff development to ensure that such changes are properly implemented. A recent review on behalf of the Committee of Vice Chancellors and Principals of the Universities of the United Kingdom called for "Training and development opportunities [to be] available to all staff who wish to prepare themselves for teaching excellence," and the King's Fund inquiry stated that "Staff development programmes are needed not only to make teaching a more professional activity, but to help in developing a shared view of the philosophy of the medical school and to ensure that all staff work together to help students achieve the objectives of the course..." No effective changes can be expected in medical education unless staff are given the resources to implement the theories. Achieving this is another major problem facing our present system, and in subsequent articles I shall describe some of the attempts that have been made to give teaching the recognition it deserves.

\section{Whose problems are they?}

The GMC has statutory responsibility for medical education in Britain, but the day to day organisation is left largely to the individual schools. The education committee of the GMC issues regular recommendations to guide the schools and coordinates a system of regular visits to ensure that standards are maintained. In theory the GMC can refuse to recognise the qualifications of a particular school for the purposes of 
provisional registration of its graduates. In practice, however, these powers are not exercised-mainly because the council has no real option for disciplinary procedures short of derecognition of a whole coursewith the devastating implications for the students in training. Thus, although the education committee can make recommendations, it can do little to enforce them. This is one of the greatest problems with our system of medical education, and the latest consultation document issued by the GMC hints at its frustration at the failure of the schools to implement the educational reforms proposed by the council in 1980 when it called for a reduction in the factual overload in the curriculum and the promotion of self education and critical thought.'

Medical schools are funded mainly by the Department for Education and Science through the Universities Funding Council. The funding of the clinical part of the medical course has always relied on a large measure of good will, with NHS staff teaching medical students and university staff providing services for NHS patients on a "knock for knock" basis. The NHS provides additional funds (Service Increment for Teaching and Research-SIFTR ("ACTR" in Scotland, "STAR" in Northern Ireland)) to help offset the additional costs to hospitals of providing facilities for medical education. The recent reforms of the NHS and the need for tighter financial accounting led to worries that there would be great problems in identifying and allocating SIFTR funds and loss of the traditional good will between the universities and the NHS. ${ }^{1011}$ In practice the impact of the reforms has not been as great as had been feared, ${ }^{12}$ and in some ways the emergence of a market economy may empower medical schools to demand the quality of medical education they require.

The cumbersome organisation of our medical education system, with responsibility for quality resting with the GMC and for funding shared between the education and health departments, means that no single body is in a position to supervise changes. We are already at a stage where many of the problems have been identified and some solutions have been suggested, but can we actually move forwards and implement effective change?

\section{Time ripe for change}

Many people are trying to find solutions to the problems in medical education, but perhaps the two clearest leads in recent years have come from the GMC and the King's Fund. ${ }^{12}$ Both emphasise the need to reduce the factual load in the medical curriculum and encourage students to develop their skills at directing their own learning in preparation for continued education beyond university. The emphasis has shifted from absorbing medical facts to acquiring the knowledge, skills, and attitudes thought to be desirable in a modern doctor. The importance of postgraduate learning is emphasised, with basic medical education seen as only part of a continuum. The need for training in manipulating information technology to assist continued learning is recognised.

There is actually very little new in these ideas. By the end of the nineteenth century the GMC had recognised the problem of curriculum overload. In 1957 the GMC expressed concern about students tending to "concentrate their attention unduly on memorising factual data" and stated that the primary task of the medical course was "to instruct less and to educate more."13 The latest consultation document issued by the GMC is largely the result of the education committee's disappointment at the failure of medical schools to respond to recommendations issued in $1980 .{ }^{14}$ The philosophy underpinning the desirability of change has
GMC recommendations on undergraduate medical education

- Reduce excessive burden of factual information in course-probably by dedicating two thirds of course to common "core" and allowing students to spend one third of their time on series of "options," in which they could study selected subjects in more depth

- Introduce substantial component of problem based learning

- Provide early clinical contact

- Ensure that all students develop firm understanding of scientific method

not altered substantially for decades, so why has nothing happened, and can it now?

Change on any great scale is disruptive and can be expensive. Medicine is a conservative profession, with high regard for old institutions and a tendency to assume that a system that worked well in the past should be preserved. But new forces are now driving change in medicine in general and medical education in particular.

The role of doctors has changed out of all recognition in recent decades. All are now expected to undertake higher specialist training and to work in multidisciplinary teams. Some of their traditional tasks are now done by other professionals. Changing work patterns for groups like nurses, pharmacists, social workers, and paramedical technicians have altered the role of doctors and in many cases replaced it. Doctors are no longer the automatic team leaders. Many members of the public do not remember life before the NHS and there is no longer an unquestioning gratitude and acceptance of what the doctor says and does. The public is increasingly well informed about medical matters and aware of its role in funding health care. The medical profession is having to be more accountable for the way in which it spends taxpayers' money.

Doctors have changed too. Increasingly they are demanding the right to lives outside their jobs. It is no longer unthinkable to want a family life as well as a career. ${ }^{5}$ Evidence is slowly emerging that those doctors who are most well rounded as individuals may also be the best at empathising and communicating with patients, leading to suggestions that "survival of the fittest" may not be survival of the best. ${ }^{3}$ High salaries and prestige have been whittled away and no longer compensate for poor working conditions. It is becoming harder to "sell" medicine as a career option to school leavers, and this is reflected in reduced numbers of people applying for places in medical school. ${ }^{15}$

Changes in the provision of medical services are also having profound effects. ${ }^{16}$ Technological developments allow rapid, minimally invasive investigations and treatments; cost implications discourage long inpatient stays; and growing emphasis on health promotion and disease prevention is shifting health care into the community.

All of these factors are affecting the way in which medicine is taught. The traditional teaching hospitals are no longer the only or best places to train doctors for the twenty first century. Change is inevitable and is currently being driven by pressures other than educational theory. If we can use the opportunity to direct some of the changes in line with desired educational principles we may achieve more in the next decade than we have done in the past century.

\footnotetext{
1 General Medical Council. Undergraduate medical education. London: GMC 1991. (Discussion document by working party of GMC education committee.)

2 Towle A. Critical thinking. The future of undergraduate medical education. London: King's Fund Centre, 199

Firth-Cozens J. Stress in medical undergraduates and house officers.
} Brf Hosp Med 1989;41:161-4. 
4 Firth-Cozens J. Emotional distress in junior house officers. BMf 1987;295: 533-5.

5 Allen I. Any room at the top? A study of doctors and their careers. London: Policy Studies Institute, 1988.

6 Dillner L. The road to disenchantment. BMF 1992;305:1103.

7 British Medical Association. Stress and the medical profession. London: BMA, 1992.

8 Harden RM, Sowden S, Dunn WR. Some educational strategies in curriculum development: the SPICES model. Med Educ 1984;18:284-97.

9 Elton L Partington P. Teaching standards and excellence in higher education. Developing a culture for quality. Sheffield: Committee of Vice Chancellors and Developing a culture for quality. Sheffield. Committee of Vice

10 Secretaries of State for Health, Wales, Northern Ireland, and Scotland. Working for patients. London: HMSO, 1989. (Cmnd 555.)

11 Universities Funding Council Medical Committee. First report on the effects of the NHS reforms on medical and dental education and research. London: UFC

12 Universities Funding Council Medical Committee. Second report on the effects of the NHS reforms on medical and dental education and research. London: UFC, 1992.

13 General Medical Council. Recommendations as to the medical curriculum London: GMC, 1957.

14 General Medical Council. Recommendations on basic medical education. London: GMC Education Committee, 1980.

15 McManus C, Lockwood D. Medical education, training and research. In: Beck E, Lonsdale S, Newman S, Patterson D, eds. In the best of health The status and future of health care in the UK. London: Chapman and Hall, The 1992 .

16 Stocking B. Medical advances. The future shape of acute services. London King's Fund, 1992

\title{
London after Tomlinson
}

\section{Maintaining excellence: the preservation and development of specialised services}

\author{
Liam J Donaldson
}

This is the fourth article in our series looking at the issues highlighted by the Tomlinson report into London's health care and medical research and education
Northern Regional Health Authority, Newcastle upon Tyne NE6 4PY

Liam J Donaldson, regional general manager and professor of applied epidemiology

$B M 7$ 1992;305:1280-3
The advent of the Tomlinson inquiry draws attention to the need to strike a balance between market led and planned approaches to health care delivery. This is important not just for hospital rationalisation but also for the preservation and development of services which are provided in a smaller number of hospitals. Specialised services are often in the forefront of raising standards of care and introducing new developments and innovations. They are the only option for a small number of patients with serious illnesses. In the internal market for health care provision created by the 1990 NHS reforms more sophisticated and flexible mechanisms must be found to provide stability for specialised services while at the same time enabling the benefits of purchaser choice and provider competition to be realised.

\section{Introduction}

The introduction of health care markets was one of the fundamental pillars of the white paper Working for Patients. ${ }^{1}$ The proposals and subsequent legislation contained several key ingredients: the creation of an environment of competition among providers of services with the aim of reducing costs and raising quality; greater choice for, and more emphasis on, consumers of health services; greater accountability of professionals; and funding mechanisms which rewarded services sought after by patients and referring general practitioners.

In the early days of the NHS reforms purists ruled. The word "planning" was all but expunged from the lexicon of health service management and the former attempts of the NHS to plan in detail the nature and location of services were viewed as outmoded. There was complete faith that the forces released in the new market would both accomplish rationalisation of services not required to meet the needs of local populations and enable the emergence of new and improved services. It rapidly became apparent that the existence of entirely untrammelled markets would inevitably mean that some clinical departments and even some whole hospitals would quickly fail to retain a foothold in the new system of care. The spectre of bed closures and service rationalisation on a large scale would have been as controversial as it was under the old arrangements and would hardly have struck the public as a beneficial aspect of reforms that were working in their ultimate interests.

Together this general context and the scale of

\section{Potential functions of a specialist centre \\ - Service delivery - Postgraduate training \\ - Research - Benchmark for good practice \\ - Innovation - Advice and devolution of skill}

potential problems in London led to the Tomlinson inquiry. ${ }^{2}$ Its very establishment, however, raises questions about future mechanisms for change and development of services in the National Health Service. Aside from its specific recommendations for London, and its predictions about the appropriate balance between primary and hospital care, the importance of the Tomlinson report lies in whether the approach signals a return to planned solutions for difficult problems as distinct from purely market led change.

\section{Planned and market led approaches}

Striking an appropriate balance between planned and market led approaches is as relevant to considering how best to preserve and develop those specialised services which are concentrated in a small number of hospitals as it is to rationalisation. Concern has constantly resurfaced, particularly in professional circles, about the ability of the new market system to preserve highly specialised services or foster new ones. In neonatal care, for example, fears expressed by witnesses to the parliamentary select committee on health that the impact of the internal market will lead to a fragmentation of regional services and devolution of expertise into a multiplicity of small provider units led the committee to conclude: "We are not persuaded that the establishment of contracts for regional services for perinatal and neonatal intensive care can be left to market forces and audit." 3

Under the new arrangements the configuration of specialist services will be determined ultimately by whether purchasers see a need for them and then through the resulting contracting mechanisms to secure and fund the care required. In theory there should be no difficulty. The purchasers of care (district health authorities and fundholding practices) are responsible for assessing and meeting the needs of their populations. Their decisions should enable people with clinical need who require services not available in a local hospital to receive them. However, the process through which need results in a decision to purchase is 